\title{
A experiência do educar para o sensível no ambiente escolar: ações e reações dentro e fora da escola do PIBID Pedagogia anos iniciais
}

\author{
Victória Jantsch Kroth* \\ Francielle Rodrigues Assunção** \\ Gabriela Gonçalves Neto*** \\ Stephanie Ferrugem Piovezan ${ }^{* * *}$ \\ Daniele Noal Gai**** \\ Dóris Bittencourt Almeida**
}

\section{Resumo:}

Vivenciar a prática da docência durante a licenciatura é um dos maiores sonhos e desafios para os graduandos, visto que contribui imensamente na sua formação. A partir da implementação do subprojeto PIBID Pedagogia Anos Iniciais/UFRGS, que se propõe a trabalhar a diversidade cultural, emergiu a possibilidade de trabalharmos o tema da educação do sensível dentro da escola contemplada. Junto a isso, em razão dos 50 anos de fundação da escola, aliamos o tema sensível à história da Anne Frank, personagem que dá nome à escola atendida. Neste artigo, procuramos apresentar algumas atividades realizadas, evidenciando que a prática da docência compartilhada, desenvolvida durante as aulas do PIBID, proporciona uma maior interação entre alunos, professores e graduandas de Pedagogia, além de como esse tema vem provocando singelas, mas importantes mudanças para a formação de todos os envolvidos.

\section{Palavras-chave:}

PIBID. Diversidade cultural. Educação sensível.

\begin{abstract}
:
Experiencing the practice of teaching during graduation is one of the biggest dreams and challenges for undergraduates, since it contributes immensely in their training. From the implementation of the PIBID subproject Pedagogia Anos Iniciais/UFRGS, which proposes to work on cultural diversity, the possibility of working the theme of education of the sensitive within the school emerged. Along with this, due to the 50th anniversary of the foundation of the school, we combined the theme sensitive to the history of Anne Frank, character that gives name to the school attended. In this article, we present some activities carried out, evidencing that the practice of shared teaching, developed during PIBID classes, provides a greater interaction among students, teachers and undergraduate students of Pedagogy, as well as how this theme has been provoking simple but important changes for the formation of all involved.
\end{abstract}

\section{Keywords:}

PIBID. Cultural diversity. Sensitive education.

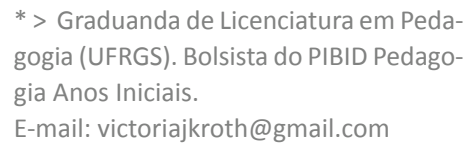

* > Graduanda de Licenciatura em Pedagogia (UFRGS). Bolsista do PIBID Pedagogia Anos Iniciais.

E-mail: victoriajkroth@gmail.com

** > Graduanda de Licenciatura em Pedagogia (UFRGS). Bolsista no PIBID Pedagogia Anos Iniciais. E-mail: francielle.rodrigues94@hotmail.com

*** > Graduando de Licenciatura em Pedagogia (UFRGS). Bolsista do PIBID Pedagogia Anos Iniciais.

E-mail: gabineto_@hotmail.com

**** > Graduanda de Licenciatura em Pedagogia (UFRGS). Bolsista do PIBID Pedagogia Anos Iniciais.

E-mail: piovezansf@gmail.com

$* * * * *>$ Doutora em Educação, Faculdade de Educação (UFRGS).

E-mail: daninoal@gmail.com

Doutora em Educação, Facul dade de Educação (UFRGS). E-mail: almeida.doris@gmail.com 


\section{Introdução}

Sabe-se que os processos de escolarizaç̃o no Brasil, notadamente nas escolas públicas, enfrentam momentos delicados, de relevância, luta e resistência. Junto a isso, a falta de investimentos, valorização e, até mesmo, preparação por parte dos docentes evidenciam ainda mais essa situação de crise e a necessidade de mudança. Por isso, preciso indicar aos estudantes possibilidades de construir uma nova realidade social e educacional, instigando-os a participarem como protagonistas, junto aos professores, desse processo de construção e transformação.

Entretanto, para que os alunos sintam-se incitados e motivados à mudança, é necessário que o mesmo ocorra com os professores. De acordo com Freire (1997, p. 19):

O aprendizado do ensinante ao ensinar não se dá necessariamente através da retificação que $o$ aprendiz lhe faça de erros cometidos. $O$ aprendizado do ensinante ao ensinar se verifica à medida em que o ensinante, humilde, aberto, se ache permanentemente disponível a repensar o pensado, rever-se em suas posiçōes; em que procura envolver-se com a curiosidade dos alunos e dos diferentes caminhos e veredas, que ela os faz percorrer.

Sendo assim, é necessário que os professores mudem, repensem e atualizem suas práticas pedagógicas relacionando-as com as distintas realidades vividas nas salas de aul Portanto, experienciar diferentes práticas pedagógicas, reconhecer e valorizar as vivências dos alunos, bem como conhecer o cotidiano em uma sala de aula e seus desafios, são essenciais para qualificar um bom professor e dar um passo para a mudança.

\section{O Programa e a Escolha do Tema}

Na intenção de aproximar os graduandos das diversas áreas de Licenciatura da realidade escolar, o governo implementou, em 2007, o Programa Institucional de Bolsa de Iniciação à Docência (PIBID). De acordo com a Capes (2016), o PIBID anseia aperfeiçoar e valorizar a formação de professores para a educação básica. Além disso, "[...] faz uma articulação entre a educação superior, a escola e os sistemas estaduais e municipais” (MEC).

No curso de Pedagogia da Universidade Federal do Rio Grande do Sul (UFRGS), PIBID mantém três subprojetos ativos, sendo eles: Pedagogia Anos Iniciais, Educação de Jovens e Adultos e Interdisciplinar, este último, relacionando Pedagogia e Artes. Os relatos de experiências discutidos nesse artigo são de uma Escola atendida pelo PIBID Pedagogia Anos Iniciais, constituído por um grupo de 10 bolsistas, 2 professoras coordenadoras e 2 supervisoras, que atuam em duas escolas da rede Pública Estadual. Semanalmente, são realizadas reuniões com o grupo, para discutir assuntos pertinentes ao tema e planeja as atividades, na busca pelo aperfeiçoamento da formação docente.

Com o intuito de instigar as crianças a refletirem acerca da sociedade em que vivemos, e, principalmente, sobre seu cotidiano, é que o tema "Dentro e fora da Escola: Como sentimos o mundo?”, fundamentado nos postulados da Educação do Sensível, fo escolhido para ser abordado nas aulas do PIBID. Evidencia-se aí a importância de trabalhar com temáticas por vezes consideradas corriqueiras e normais, no sentido de fomentar o desenvolvimento do senso crítico dos estudantes, além de valorizar as coisas simples da vida.

Para as reuniões de formação das Pibidianas, trabalhamos, como referencial teórico, o livro O sentido dos sentidos: a educação (do) sensível, de João-Francisco Duarte Junior. Nele, Duarte Jr. (2001) destaca a educação do sensível como o momento em que os educadores voltam sua atenção para o "saber primeiro", que foi sendo desprezado pelo conhecimento intelectivo nos ambientes escolares, familiares e sociais de nossa vida cotidiana. Em suas palavras

Investir-se numa educação do sensivel significa não somente o desenvolvimento de pescos

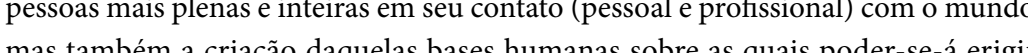
movos par̂m a craçao daquelas bases humas do sobre as quais poder-se-á erigir novos paranetros do con ou holisticos. Ea ainda a educaçao do sensivel devera, de maneira reflexa, implicar numa educação mais sensivel em si propria, isto é, menos interessada na quantidade de informaçăo a ser transsilita do que na submetidos (DUARTE JR, 2001, p. 34).

O autor também relata no livro que estamos passando pela "crise da Modernidade", e afirma que a mesma deve ser trazida e observada em nosso próprio cotidiano, nossa processo distante e bstrato Com isso baseado nas ideias de Kujawski (1991), Duarte Junior apresenta no livro verbos que estão diretamente ligados a nossa vida e muitas vezes são banalizados, como morar, caminhar, conversar, comer e trabalhar, que merecem ser refletidos, repensados e valorizados, sobretudo considerando a perspectiva de uma educação para o sensível.

Nas escolas contempladas pelo PIBID, em que tratamos do tema sensível, no dividimos entre cinco discentes de Licenciatura em Pedagogia e atuamos em três turmas, sendo elas $3^{\circ}, 4^{\circ} \mathrm{e} 5^{\circ}$ ano do Ensino Fundamental, tendo em média vinte alunos cada. Vale ressaltar que trabalhamos com cada turma separadamente, durante um período de 50 minutos, e que o projeto, bem como as atividades, são pensados e planejados de uma forma que possam ser introduzidos de maneira semelhante nas três turmas, respeitando a faixa etária dos alunos e abrangendo cada um na sua individualidade.

\section{Escola, História e o Sensível}

Neste ano de 2016, a Escola Estadual de Ensino Médio Anne Frank, na qual implementamos o projeto da educação do sensivel pelo PIBID, completou 50 anos. Portanto, decidimos, com a ajuda das professoras que nos acompanham, abordar em sala de aula a educação sensivel relacionada com a história da Anne Frank.

Mas como trabalhar temáticas tão complexas, em que estão implicados fatos da História como a Segunda Guerra Mundial, o nazismo e o holocausto com crianças? Pensando nisso, surgiu a ideia de lermos o livro A menina que ficou invisivel (PORTELLA, 2012), de Valéria Portella, que é bem explicativo e possui uma linguagem simples para os alunos conhecerem melhor a história de Anne Frank. Em seguida, propusemos aos estudantes a criação de um diário pessoal, em que pudessem registrar temas cotidianos, tal como fazia Anne Frank, a protagonista da história. A partir de Larrosa (1998), compreendemos que como que um presente, escolhemos esse livro para aguçarmos as indagações dos alunos e formarmos seres pensantes, publicizando a simbologia que traz o livro e seu tema sensível.

Anne Frank foi uma menina alemã, de origem judaica, que nasceu em Frankfurt. Com a ascensão do nazismo e ao receberem uma proposta de emprego, os pais de Anne optaram pela mudança para Amsterdã. Após certo tempo, os alemães invadiram a Holand a dois anos A família foi descober dois anos. A familia foi desc campos de concentração. A guerra acabou em 1945 e dentre os 8 moradores do anexo, somente o pai de Anne sobreviveu (FRANK; PRESSLER, 2013). 
Anne, durante o tempo em que estava escondida, possuía um diário em que relatava as experiências vividas durante o momento delicado e turbulento que seu pais e seu povo viviam, fato que inspirou-nos a propor aos alunos a produção de seus próprios diários. Sendo considerado algo pessoal e sensível, oportunizamos aos alunos a possibilidade de confeccionar seu próprio diário e expressar seus sentimentos e emoções no mesmo, tornando-se uma lembrança da infância, do que pensam, gostam e fazem.

Um dos nossos impulsores para a execução deste projeto foi também a historicidad do bairro onde se localiza a escola. O Bairro Bom fim, de Porto Alegre, foi construído por famílias de origem judaica que encontraram um local para se refugiar e reconstruírem suas vidas, valorizando suas práticas culturais.

Os alunos, apesar de alguns virem de diversos locais de Porto Alegre e regiões metropolitanas, moram em sua maioria neste bairro, o que intensificou a importância de trabalhar com a história local, integrada à cultura e aliada ao presente na forma de um diário, pois história local "[...] refere-se ao conhecimento histórico, sob a perspectiva local e pode significar: o local como objeto do conhecimento e/ou o local como referência para o conhecimento" (NEVES, 1997, p. 15, grifo do autor).

Introduzimos o tema explicando aos alunos que trabalharíamos sobre a história da Anne Frank relacionada com a Educação do Sensível, e fizemos alguns questionamentos no sentido de conhecermos quais eram seus conhecimentos a respeito dela e de sua vida. Para nosso espanto, a maioria dos alunos do $5^{\circ}$ ano não sabia nada sobre quem foi Anne Frank, onde viveu, em que momento, o que aconteceu com ela, entre outras informações. Diante dessa situação, precisamos apresentar um breve resumo da vida de Anne, relacionando ao contexto histórico daquele momento, para que compreendessem nossos objetivos. Ji as crianças do $3^{\circ} \mathrm{e} 4^{\circ}$ ano haviam estudado um pouco da história da menina e tinham bastante conhecimento sobre a $2^{\mathrm{a}}$ Guerra mundial e a conjuntura da época.

As aulas, referentes à elaboração do diário, iniciavam com a leitura de um trecho $d$ livro aos alunos, seguida por uma atividade relativa ao assunto tratado no texto, que, na maioria das vezes, se relacionava à educação do sensível e aos verbos citados por Duarte Junior. Dividimos o diário em sete partes, sendo elas: 1) autobiografia, onde escreveram o que achavam importante sobre si; 2) capa, em que confeccionaram a capa do diário e foi momento do ápice da imaginação para alguns; 3) parte da casa, relatando o local em que se sentiam confortáveis dentro de suas casas e o motivo; 4) brincadeiras e brinquedos que gostavam ou gostam; 5) caminho, explicando por meio de desenho e/ou escrita o trajeto da casa até a escola destacando os lugares que mais gostam; 6) sonhos, o que eles almejan ser ou alcancar futuramente; 7) e um presente criativo, momento no qual eles deveriam imaginar um presente maluco que alguém gostaria de receber.

A primeira atividade foi a elaboração da autobiografia, que seria a primeira página do diário. Inicialmente, percebemos que alguns alunos não sabiam muito bem o que escrever sobre si, mas não demorou muito para ideias surgirem, a partir de nossas intervenções. Lendo as autobiografias, descobrimos muitas curiosidades sobre os alunos, entretanto, no deparamos também com relatos que nos comoveram, como alguns que destacaremos seguir. A afetividade e o tema sensível se mostram muito próximos com o trabalho que fazemos quando percebemos que os alunos se sentem seguros ao nos relatarem coisas íntimas sobre sua história.

Uma aluna do quinto ano relatou em sua autobiografia, de forma aparentemente descontraida, a morte do pai, justificando a escolha do time para o qual torce e contando que, antes, ela e seu pai eram os únicos que torciam para o mesmo time e após o falecimento dele, sua irmã a convenceu a trocar de time, sentindo-se aliviada com a troca. Percebe-se aqui que algumas crianças tratam com naturalidade problemas considerados complexos, frágeis e, até mesmo, tidos como tabus para serem abordados na sala de aula, nos mostrando sua ampla capacidade de compreensão diante de determinadas situações.
A segunda atividade, realizada para compor o diário e seguindo o assunto tratado na leitura do livro, foi sobre a casa das crianças, o que elas mais gostam e o que queriam mudar nos lugares em que moram, procurando estabelecer conexões com o verbo mora bo um pouco mais da vida dos alunos e de sua composição familiar; tendo alguns com pais separados, outros morando com avós, tias, primos, e alguns que perderam familiares proximos ainda quando menores. Durante essa atividade, passamos por um momento complicado, com o relato de uma aluna do, $3^{\circ}$ ano, que declarou querer mudar em sua casa as atitudes do pai em relação à mãe.

Outra atividade proposta aos alunos foi que fizessem um desenho ou pequeno texto descrevendo o trajeto que fazem para chegar de sua casa até a escola. Nessa atividade, um aluno do terceiro ano escreveu em um dos prédios de seu desenho a frase "Fora Temer" constatamos que mesmo com pouca idade, alguns deles já reparam em assuntos de cunho político, pois veem e ouvem sobre o mesmo com certa frequência, e os reproduzem em suas atividades na sala de aula Por meio dessa atividade, observamos um relato de bullying, co na van a caminho de casa para a escola.

Figura 1 - Mistura de tintas feitas pelo aluno do 30 ano

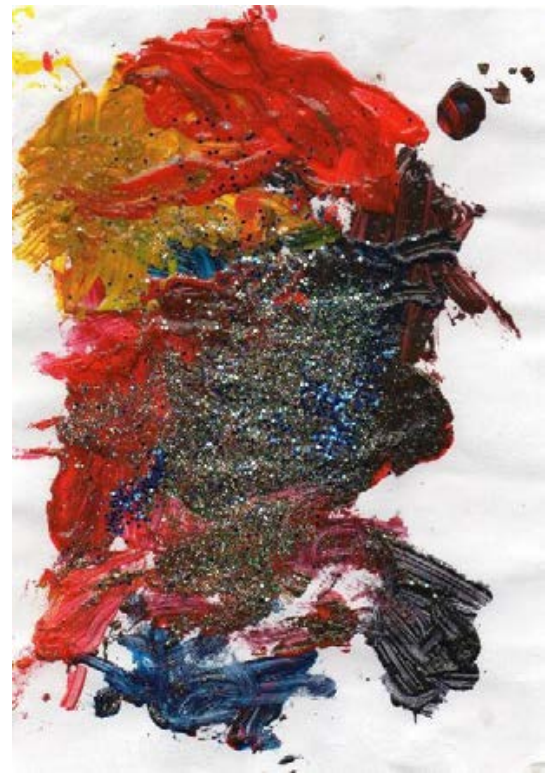

Fonte: Dados da pesquisa, 2016

A arte pode consistir num precioso instrumento para a educação do sensivel, levandonos não apenas a descobrir formas até então inusitadas de sentir e perceber o mundo, como também desenvolvendo e acurando os nossos sentimentos e percepcões acerca da realidade vivida (DUARTE JR., 2001, p. 23).

Durante nossas atividades, tentamos ao máximo adaptá-las para que todos sintaminstigados, motivados e confortáveis a realizá-las da sua própria maneira, respeitando suas capacidades e limitações, pois temos em sala de aula alunos com dificuldades de aprendizagem, hiperatividade e Sindrome de Down. Percebemos que, desse modo, ao deixá-los tranquilos e despreocupados, os alunos que possuem dificuldades se mostraram cativados pelas atividades propostas, como o exemplo de um aluno do quarto ano que de crise politica vivida no país, em que 0 presidência da Michel Temer assume a da República após o Impément da presidenta Dilma Rousseff. 
possui transtorno de hiperatividade, e se mostrou extremamente interessado em confeccionar a capa de seu diário quando percebeu que misturando as tintas poderia formar novas cores (Figura 1).

Para finalizar o semestre e também as atividades do diário, optamos por fazer uma aula diferenciada com os alunos e, para isso, convidamos um colega de faculdade, que cursa Geografia, para dar uma aula mais explicativa sobre a história de Anne Frank e a conjuntura da $2^{\mathrm{a}}$ guerra mundial. Nesta atividade, utilizamos o Mapa Múndi, para que os alunos pudessem visualizar todos os paises, e diferentes botôes, representando diversidade e a desigualdade social. Inicialmente, pedimos para que os alunos sentassem em volta do mapa e com os botões separamos os povos que tiveram envolvimento na guerra. Um botão foi escolhido pelos alunos para representar a Anne Frank, e a partir dai relembramos e explicamos onde Anne nasceu, onde se escondeu, os motivos, quem mais se escondia, por que a guerra aconteceu, quais os países envolvidos, entre outras coisa.

A atividade serviu para aguçar o interesse dos alunos por história e geografia, além de trabalhar a sensibilização com o holocausto e com as diferenças dos indivíduos, sejam em crenças, formas de agir, deficiências. A inclusão deve ser feita, e está imbricada com o sensível, para que não haja formas de intolerância, pois

[...] a autoridade de um grupo, ainda que seja a de um grupo de crianças, é sempre consideravelmente mais forte e muito mais tirânica que a de um único indivíduo, por mais severo que este possa ser. Se nos colocarmos no ponto de vista da criança tomada individualmente, apercebemo-nos de como são praticamente nulas as hipo teses que ela tem de se revoltar, ou de fazer qualquer coisa por sua própria iniciativa (ARENDT, 2007, p. 230)

Sendo assim, essa atividade constituiu-se em um meio de intervir e fazê-los repensar certos gestos, modos de agir e pensamentos coletivos que percebemos entre grupos de crianças, principalmente com os colegas que possuem alguma dificuldade. Ao fim da confecção do diário e do tema da Anne Frank, esperamos que os alunos reflitam os aprendizados e as evoluçoes no seu modo de pensar e ver o mundo em suas famílias e nos meios em que vivem, fazendo com que todos sejam respeitados na sua individualidade e valorizando os sentimentos, experiências, vivências e histórias de vida de cada um.

\section{Considerações Finais}

Em uma nova fase do projeto, a educação sensível continua como tema principal, entretanto alteramos o foco e as atividades para que não se tornassem desgastantes. Percebemos que a educação do sensível e a possibilidade através do PIBID de prestarmos docência compartilhada, proporcionou novas perspectivas aos alunos, a seus professores e a nós.

Os julgamentos através dos sentimentos e sensações tornaram-se mais comedidos nas turmas, principalmente para com os colegas deficientes ou que apresentam problemas de aprendizado. Acreditamos que cabe a nós, a escola, a família e a sociedade expor esses temas, mesmo que não descritos como essenciais para o currículo, pois percebemos sua real necessidade para compreensão da ética e do respeito.

O olhar sensível, bem como, a educação do - e para - o sensível nos fez avaliar que o aprendizado é mútuo; que não deve ser só intelectual, mas também corporal; que é preciso uma educação que foque, conjuntamente, no aprendizado para sensibilidade auxiliando na construção de um caráter e na articulação dos sentidos e sensações, facilitando a compreensão entre experiências e aprendizados curriculares. Avaliamos como desafio para a educação conseguir associar a corporeidade e o pensar de forma a trabalhar dentro de sala de aula com maior eficácia os temas sensiveis, os tabus, os preconceitos, o respeito às individualidades e a ruptura com o individualismo, almejando uma sociedade maisjusta e humana e concretizando a mudança e melhoria na forma de enin

\section{Referências}

RENDT, Hannah. A crise na educação. In: Entre o passado o o futuro. Tradução Mauro W. Barbosa de Almeida. 6. ed. São Paulo: Perspectiva, 2007. p. 221-247.

BRASIL. CAPES. PIBID: Programa Institucional de Bolsa de Iniciação à Docência. 3 set. 2008. Dis ponivel em: <http://www.capes.gov.br/educacao-basica/capespibid/pibid>. Acesso em: 18 ago. 2016. Ministério da Educação. PIBID: Apresentação. Disponível em: <http://portal.mec.gov.br/ ibid >. Acesso em: 18 ago. 2016.

DUARTE JR., João-Francisco. O sentido dos sentidos: a educação (do) sensível. Curitiba: Criar, 2001. FRANK, Otto; PRESSLER, Mirjam. O diário de Anne Frank. 38. ed. Brasil: Record, 2013.

FREIRE, Paulo. Professora sim, tia não: cartas a quem ousa ensinar. 1. ed. São Paulo: Olho d’Água, 1997. $84 \mathrm{p}$.

KUJAWSKI, Gilberto de Mello. A Crise do Século XX. 2. ed. São Paulo: Editora Ática, 1991.

LARROSA, J. Sobre a Lição: Ou do ensinar e do aprender na amizade e na liberdade. In: Pedagogia Profana: danças, piruetas e mascaradas. Porto Alegre: Contrabando, 1998. p. 173-183. NEVES, Joana. História Local e construção da identidade social. Saeculum: Revista de História, João Pessoa, n. 3, jan./dez. 1997.

PORTELLA, Valeria. A menina que ficou invisível. 1. ed. Porto Alegre: Literalis Editora, 2012. 
